\title{
Finite Element Analysis of Yamaha SZ 150 cc Motorcycle Disc Brake
}

\author{
Nilesh G.Jawarkar ${ }^{1,}$ Dr.G.K.Awari ${ }^{2}$, Dr. S. P. Trikal ${ }^{3}$ \\ ${ }^{1}$ Ph.D Scholar, Amravati, Maharashtra \\ ${ }^{2} \mathrm{HOD}$, Automobile Engineering, Govt. Polytechnic, Nagpur \\ ${ }^{3}$ Head of Mechanical Engineering Department, SSGMCE, Shegaon
}

Received on: 11 December, 2020, Revised on: 11 January, 2021 , Published on: 16 January, 2021

\begin{abstract}
Braking is a method that transforms the kinetic energy into mechanical energy which must be disintegrated in the form of heat. Braking process is nothing more than providing rotary motion resistance, resulting in a reduction of the rotating member's speed or total stoppage of that member. The frictional heat generated at the interface disc pads during the braking process will lead to high temperatures. During braking operation, the induced frictional heat causes many negative impacts on the brake system, such as brake fade, premature wear, thermal cracks and variance in disc thickness. This paper aims to present a comparison of the thermal activity of the disc brake motorcycles during the braking process using static structural and thermal analysis using finite elemental analysis for the vehicle disc brake pad method. The ANSYS workbench performed numerical study of Yamaha for various speed and mass of flywheel. Experimentally obtained results are compared with mathematical results and numerical results. The comparison of these experimental, numerical and mathematical results finds its suitability for the optimized dimensions of disc brake.
\end{abstract}

Keywords: Disc brakes; Heat flux; Temperature; FEA; Structural Analysis; Transient thermal analysis.

\section{I- INTRODUCTION}

$\mathbf{T}$ he braking mechanism is the most critical aspect of a vehicle's road safety, since it relies on the complete or systems partial detention, ultimately, a dignity of its occupants. Normally, the front disc brake absorbs \% of the kinetic energy generated also in motion and the remainder is consumed by that of the rear brake, that is normally the drum.

Both bikes utilized drum brakes through the first half of the twentieth century. Such brakes were helpful, but during the braking process they were quickly heated, a little bulky, and it was difficult to adjust the form of theirs brake shoe. Disc brakes have been used on highend bikes in the 1970s and were only mounted at a high expense on front wheel, but they were generalized in the case of cars as time progressed and due to their better working. Nowadays, both wheels have disc brakes on all medium-high-range motorbikes, and often the front wheels have two discs [1].

Subsequently, as provided by Talati and Jalalifar [2], the K.E is converted into T.E caused by friction into the pad and brake rotor where the temperature reach $900^{\circ} \mathrm{C}, \%$ of the heat is disseminated and consumed by a pad and rotor. A significant amount of high heat is produced during process of braking, this heat disseminated rapidly through a convection phenomena with the surrounding air and thus avoids reduction of friction coefficient [3], [4].

An evaluation of a geometry parameters of a discs is dependent on a capability and function of the load, which in the initial design process is a significant consideration [5], [6]. It is essential to examine the behaviour of related thermo-fluids in a design stage of ventilated disc brakes, where activity and properties of fluids centered can be studied, constantly maintaining an 


\section{International Journal of Innovations in Engineering and Science, www.ijies.net}

efficacy of a heat dissipation and surface braking mechanism and the channels for ventilation [7]. For the purpose, finite element analysis and statistical simulations allow one to validate the findings of the experimentation data that can be collected to refine the fluid dynamics and thermal properties of the disc brakes by means of CFD [8].

Heat dissipation and brake ventilated disc output are primarily based on the air flow aerodynamics properties by the airflow channels and disc brake geometry specifications [9], [10], that are tested by application of modeling tools which has CFD Library [11], [12]. In specific, because of ongoing developments into software and hardware, like advancements in computational techniques for solving equations of fluid flow. The automobile industry's interest in CFD applications stems from its potential to optimize automotive architecture and to minimize costs and increase the life cycle of products [13], [14], [15].

The disk brake is a tire brake that slows the friction generated by pressing the brake pads against a brake disc using a collection of calipers to rotate the wheel [16]. This phenomenon known as disc brake, compact disc consisting of structural brace compact disc bolt to the wheel centre and a fixed housing known as calliper, transforms action to heat, and if the brake get also hot, they become less useful [17].

Like the stub axle, the caliper is attached to a stationery section of the vehicle since each part consists of a piston cast into two parts. A frictional pad is placed in place between each piston and the disk by detainment pin, spring plates [18]. The passage for bleeding thus linked to another one. Both cylinder includes a rubber-sealing ring placed between the piston and the cylinder.

The plan be in the direction of performed numerical study of Yamaha SZ 150 cc bike disc brakes for various speeds and mass of flywheel. Experimentally obtained results are compared with mathematical results and numerical results.

\section{II- MATERIALS AND METHOD}

A foot brake is a motorcycle's mainly efficient device because it is able to produce absolute or else incomplete seize from a firm speed. For this reason, the high rate of motorcycle accidents is owing to refusal by traffic rules, improper protection and automatic malfunctions, anywhere the major things of the communication, delay and brake scheme occur [19].

A purpose of this study is to confirm the thermal property of motorcycle foot brake discs with mathematical comparison and numerical model using the Ansys simulation software for Yamaha bike, in order to determine a complete analysis of the phenomena. By reviewing the articles, it was noted, most disc brakes are nodular gray cast iron with laminar graphite, silicone and manganese, taking into account the reference [20], [21]. The numerical techniques are based on the laws describing transfer of heat and analytical solutions. Realistic problems, however, occupy complex boundary conditions and geometries, which are variable characteristic that can't be analytically solved [22].

The mathematical method provides solution inside the limit of the problem for discrete points and offer an estimate of the correct solution. On the other hand the method of solving a system simultaneous algebraic equations, instead of a differential equation, is simplified when trade by a solution for a fixed number of separate points. Individual the solution to instantaneous equations, computers are the perect task. This happens during the discretization of the domain in query, with discretization mortal the substitution in a system of numerical equations of differential equations [23]. Figure 1 shows the Disc brake of Yamaha SZ $150 \mathrm{cc}$ motorcycle

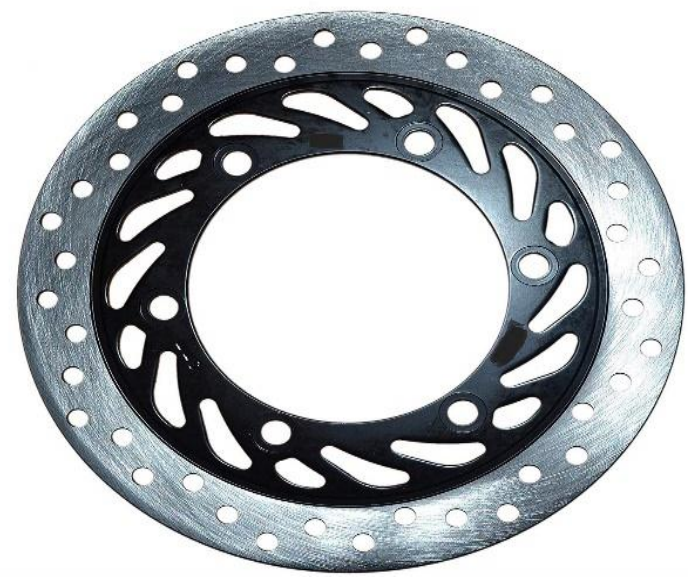

Fig 1- Disc brake of Yamaha SZ

This is important to remember that it is necessary to discretize the preventing or early conditions particular for the problem and that what is obtained from the software is an approximation to the exact solution, the numerical method can generate error in the solution, so it is necessary to know how to analyze and diminish these errors [24]. 


\section{International Journal of Innovations in Engineering and Science, www.ijies.net}

\section{III- THE FINITE ELEMENT ANALYSIS OF YAMAHA SZ 150 CC MOTORCYCLE DISC BRAKE}

A FEA is a physical problem modeling approach using a computational approach that is also known as FEM. Experts have sought to eliminate a range of challenging models, to simplify items easily by redesigning parts in their structure process to improve efficiently. FEA is a computational technique used under defined conditions to predict how a region or assembly works together. In carrying out thermal evaluation on a brake assembly together the FEA process has recently become a preferred system. It is reported that thermal analysis is normally conducted using a finite component approach, since this technique has become an excellent resource for a wide variety of structural problems for a numerical game plan [25].

In 1970, Dr. John Swanson founded ANSYS with the aim of encouraging the possibility of a machine replicated structure, identifying himself as one of the founders of finite element analysis (FEA). The ANSYS programming group is all about useful finite element evaluation (FEA). In brake applications, ANSYS 15 is used entirely to recreate assistant deformation, temperature, stress and pressure distribution. A 3-D FE model contains a solid disc \& two pads are used in the present work. Figure 2 shows th 3D model of disc plate Yamaha SZ 150 cc motorcycle.

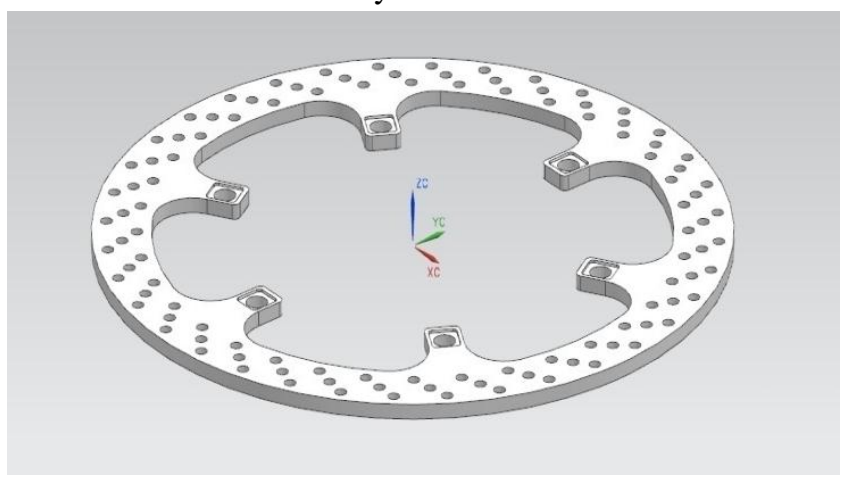

Fig 2-3D model of disc plate Yamaha

The experimentation was also performed with different combinations of speed, disc diameter and mass of flywheel. During the experimentation, different readings were recorded. The experimental values were analyzed by the numerical analysis and compared. On the basis of readings and comparison of experimental and numerical, following results were analyzed for the structural and thermal point of view and also weight optimization is given.

The numerical analysis of disc brake of Yamaha SZ is conducted in the ANSYS workbench for different speed. The very first analysis is conducted for the deformation of disc for different speeds. The analysis was done with the rpm of 500,600 and 700 .

\section{IV- RESULTS AND DISCUSSIONS}

A vehicle's kinetic and potential energy is rapidly converted into thermal energy produced by the brakes. In order for the braking system to operate properly, taking into consideration the above the heat produced must dissipate as rapidly as possible to prevent the system from overheating, thus undermining the system's efficiency and protection. Via convection and radiation, the rotation of the vehicle facilitates heat dissipation. But extreme (repetitive) braking allows the temperature, known as the saturation temperature, to increase to a certain level, which depends on the brake disc's thermal dissipation power, determined by the type of geometry and the type of brake material. We obtained the thermal properties of the Yamaha SZ 150 cc motorcycle disc brake in this report.

The numerical analysis of disc brake of Yamaha SZ is conducted in the ANSYS workbench for different speed. The very first analysis is conducted for the deformation of disc for different speeds. The analysis was done with the rpm of 500, 600 and 700. It has been observed that at lowest speed i.e. $500 \mathrm{rpm}$ when brakes are applied, the total deformation was small i.e. $2.77 \times 10-4 \mathrm{~mm}$. The deformation is increases as the speed increases. It can be seen when speed is $600 \mathrm{rpm}$ the deformation found to be $3.71 \times 10-4 \mathrm{~mm}$. The maximum deformation found at 700 rpm i.e. $4.50 \times 10-4 \mathrm{~mm}$. From the graph it is concluded for the disc of Yamaha SZ, as speed increases its deformation also get increases when brakes are applied. Figure 3 shows the total deformation of Yamaha Bike for different Speeds.

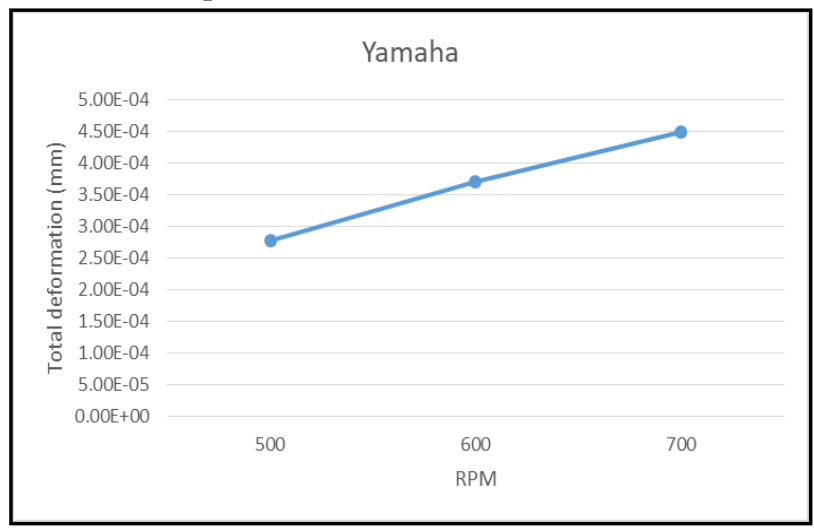

Fig 3.- Total Deformation of Yamaha Bike for different Speeds 


\section{International Journal of Innovations in Engineering and Science, www.ijies.net}

The numerical analysis of disc brake of Yamaha SZ is conducted in the ANSYS workbench for different speed. The analysis is conducted for the deformation of disc for different speeds. The analysis was done with the rpm of 500, 600 and 700 as shown in figure 4 (a), (b), and (c) respectively. The maximum deformation is seen at outermost diameter. The maximum deformation for 500 , 600 and $700 \mathrm{rpm}$ were $0.000277 \mathrm{~mm}, 0.000371 \mathrm{~mm}$ and $0.000449 \mathrm{~mm}$ respectively.

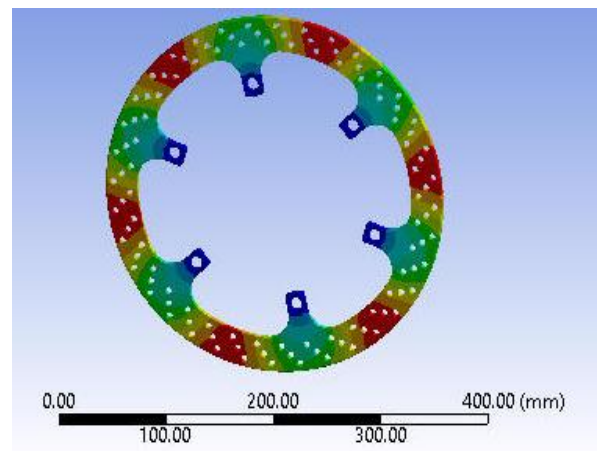

(a)

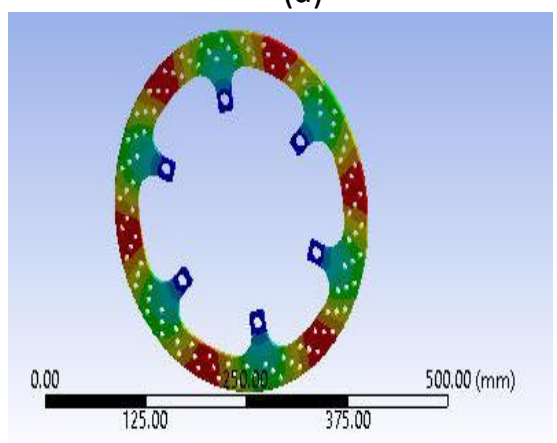

(b)

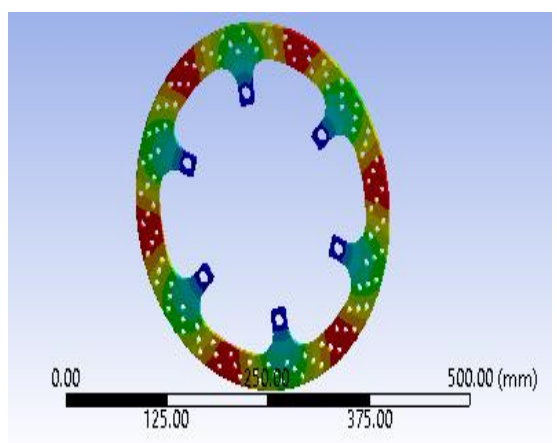

(c)

Fig 4- Disc analysis (a) for $500 \mathrm{rpm}$, (b) for $600 \mathrm{rpm}$ and (c) for $700 \mathrm{rpm}$

\section{V- CONCLUSIONS}

The method considered and measured by the research authors was largely suitable, since elements under review are readily available and virtually all motorcycles presently have two-wheel ventilated disc brakes for an efficient braking operation. In the opposite, cars that prefer to use the rear axle drum brakes produce substantial drawbacks into braking processing, like humidity, heat loss, and hence corrosion problem which influences braking process.

Current research aims to learn connection between structure of the disc brake and best braking efficiency in terms of the speed of heat dissipation into a surroundings. Results show the ratio of heat dissipation speed with the higher motorcycle displacement capability is proportional to speed of action of bike; thus, the better thermal properties of the device are considered for the disc brake.

The maximum deformation is seen at outermost diameter. The maximum deformation for 500, 600 and $700 \mathrm{rpm}$ were $0.000277 \mathrm{~mm}, 0.000371 \mathrm{~mm}$ and $0.000449 \mathrm{~mm}$ respectively.

Finally, the use of the FEA modeling tools is of considerable significance because the operating conditions of the disc brakes can be studied, checked and evaluated and the behavior that takes place in these braking systems can be illustrated in this way.

\section{REFERENCES}

[1] Criado, E. (2012), Diseño y cálculo del sistema de frenado para un prototipo formula student, Universidad Carlos III de Madrid, Madrid, España.

[2] Talati, F. and Jalalifar, S. (2009), "Analysis of heat conduction in a disk brake system", Heat and Mass Transfer, Vol. 45 No. 8, pp. 1047-1059, doi: 10.1007/s00231-009-0476-y.

[3] K. C. Nikam, R. Kumar, and R. Jilte, "Economic and exergoeconomic investigation of $660 \mathrm{MW}$ coal-fired power plant," J. Therm. Anal. Calorim., 2020, doi: 10.1007/s10973-020-10213-z.

[4] Todeschini, F., Corno, M., Panzani, G., Fiorenti, S. and Savaresi, S.M. (2014), "Adaptive position-pressure control of a brake by wire actuator for sport motorcycles", European Journal of Control, Vol. 20 No. 2, pp. 79-86, doi: 10.1016/j.ejcon.2013.12.003.

[5] García-León, R.A. and Perez Rojas, E. (2017), "Analysis of the amount of heat flow between cooling channels in three vented brake discs", Ingenieria y Universidad, Vol. 21 No. 1, pp. 55-70, doi: 10.11144/Javeriana.iyu21-1.aahf.

[6] Bocîi, L.S. (2011), "The influence of braking time on heat flow through the friction surfaces of the friction elements of disk brakes for railway vehicles", Transport, Vol. 26 No. 1, pp. 75-78, doi: 10.3846/16484142.2011.563494. 


\section{International Journal of Innovations in Engineering and Science, www.ijies.net}

[7] Yan, H.B., Yan, H.B., Feng, S.S., Yang, X.H. and Lu, T.J. (2015), "Role of cross-drilled holes in enhanced cooling of ventilated brake discs", Applied Thermal Engineering, Vol. 91, pp. 318-333, doi: 10.1016/j.applthermaleng.2015.08.042.

[8] García-León, R.A. (2017), "Thermal study in three vented brake discs, using the finite element analysis", DYNA (Colombia), Vol. 84 No. 200, pp. 19-27, available at: http://dx.doi.org/10.15446/ dyna.v84n200.55663

[9] Chi, Z., He, Y. and Naterer, G. (2009), "Convective heat transfer optimization of automotive brake discs", SAE International Journal of Passenger Cars - Mechanical Systems, Vol. 2 No. 1, pp. 961-969, doi: 10.4271/200901-0859.

[10] K. C. Nikam, R. Kumar, and R. Jilte, "Thermodynamic modeling and performance evaluation of $a$ supercritical coal-fired power plant situated in Western India," Energy Sources, Part A Recover. Util. Environ. Eff., vol. 00, no. 00, pp. 1-19, 2020, doi: 10.1080/15567036.2020.1806410.

[11] Adamowicz, A. and Grzes, P. (2011), "Influence of convective cooling on a disc brake temperature distribution during repetitive braking", Applied Thermal Engineering, Vol. 31 Nos 14-15, pp. $2177-$ 2185, doi: 10.1016/j.applthermaleng.2011.05.016.

[12] Ho, Y.-H., Ho, Y.-H., Athavale, M.M., Forry, J.M., Hendricks, R.C. and Steinetz, B.M. (1996), "Numerical simulation of secondary flowin gas turbine disc cavities", Including Conjugate Heat Transfer, Paper No. 96-GT-067, V001T01A023, Vol. 1, Turbomachinery, 8pp., available at: https://doi.org/ 10.1115/96-GT-067

[13] Pevec, M., Potrc, I., Bombek, G. and Vranesevic, D. (2012), "Prediction of the cooling factors of a vehicle brake disc and its influence on the results of a thermal numerical simulation", International Journal of Automotive Technology, Vol. 13 No. 5, pp. 725-733, doi: 10.1007/s12239-012-0071-y

[14] K. C. Nikam, R. Kumar, and R. Jilte, "Exergy and exergo-environmental analysis of a $660 \mathrm{MW}$ supercritical coal-fired power plant," J. Therm. Anal. Calorim., no. 0123456789, 2020, doi: 10.1007/s10973020-10268-y

[15] Wurm, J., Fitl, M., Gumpesberger, M., Väisänen, E. and Hochenauer, C. (2016), "Novel CFD approach for the thermal analysis of a continuous variable transmission (CVT)", Applied Thermal Engineering, Vol. 103, pp. 159-169, available at: https://doi.org/10.1016/j.applthermaleng. 2016.04.092

[16] Shelare S.D., Kumar R., Khope P.B. (2021) Formulation of a Mathematical Model for Quantity of Deshelled Nut in Charoli Nut Deshelling Machine. In: Prakash C., Krolczyk G., Singh S., Pramanik A. (eds) Advances in Metrology and Measurement of Engineering Surfaces. Lecture Notes in Mechanical Engineering. Springer, Singapore
[17] Waghmare S., Shelare S., Sirsat P., Pathare N, Awatade S. (2020) Development of An Innovative MultiOperational Furnace. International Journal of Scientific \& Technology Research Volume 9, Issue 04, April 2020. Pp 885-889.

[18] Waghmare S., Mungle N., Tembhurkar C., Shelare S., Sirsat P., Pathare N. (2019) Design and Analysis of Power Screw for Manhole Cover Lifter. International Journal of Recent Technology and Engineering, Volume 8, Issue 2, July 2019. Pp. 2782-2786, DOI: 10.35940/ijrte.B2628.078219

[19] García-León, R.A., Echavez-díaz, R.D. and FlórezSolano, E. (2018), "Thermodynamic analysis of an automotive brake disc with ventilation pillars NACA type 66-209", IngeCUC, Vol. 14 No. 2, pp. 9-18.

[20] Pan, L., Jianmin, H., Zhiqiang, L., Zhiyong, Y. and Weijing, L. (2015), "Numerical simulation for train brake disc ventilation”, Beijing Jiaotong Daxue Xuebao/Journal of Beijing Jiaotong University, Vol. 39 No. 1, pp. 118-124, doi: 10.11860/j.issn.1673-02912015.01.020.

[21] Waghmare S., Sirsat P., Sakhale C., Shelare S., Awatade S. (2017) A Case Study on Improvement of Plant Layout for Effective Production. International Journal of Mechanical and Production Engineering Research and Development, Volume 7, Issue 5, Oct 2017. Pp. 155-160

[22] Jawalekar, S. B., and S. D. Shelare. 2020. Development and performance analysis of low cost combined harvester for rabicrops. Agricultural Engineering International: CIGR Journal, 22 (1):197-201.

[23] Waghmare S.N., Sakhale C.N., Tembhurkar C.K., Shelare S.D. (2020) Assessment of Average Resistive Torque for Human-Powered Stirrup Making Process. In: Iyer B., Deshpande P., Sharma S., Shiurkar U. (eds) Computing in Engineering and Technology. Advances in Intelligent Systems and Computing, vol 1025. Springer, Singapore

[24] Jiménez, R. (2011), "Influencia de los elementos grafitizantes sobre las propiedades mecánicas $y$ térmicas de un disco de freno automotriz de hierro gris hipereutéctico", tesis de posgrado en ingeniería de manufactura, Instituto Politecnico Nacional, ciudad de Mexico, Mexico.

[25] Mathew J.J., Sakhale C.N., Shelare S.D. (2020) Latest Trends in Sheet Metal Components and Its ProcessesA Literature Review. In: Sharma H., Govindan K., Poonia R., Kumar S., El-Medany W. (eds) Advances in Computing and Intelligent Systems. Algorithms for Intelligent Systems. Springer, Singapore 